\title{
Making Waves Perspectives of Modelling and Monitoring of SARS-CoV-2 in Aquatic Environment for COVID-19 Pandemic
}

\author{
Manish Kumar ${ }^{1,2}(\mathbb{D}) \cdot$ Sanjeeb Mohapatra ${ }^{3} \cdot$ Payal Mazumder $^{4} \cdot$ Ashwin Singh $^{5} \cdot$ Ryo Honda $^{6} \cdot$ Chuxia Lin $^{7}$. \\ Rina Kumari ${ }^{8} \cdot$ Ritusmita Goswami $^{9} \cdot$ Pawan Kumar Jha $^{10} \cdot$ Meththika Vithanage $^{11} \cdot$ Keisuke Kuroda $^{12}$
}

Published online: 12 September 2020

(C) Springer Nature Switzerland AG 2020

\begin{abstract}
Prevalence of SARS-CoV-2 in the aquatic environment pertaining to the COVID-19 pandemic has been a global concern. Though SARS-CoV-2 is known as a respiratory virus, its detection in faecal matter and wastewater demonstrates its enteric involvement resulting in vulnerable aquatic environment. Here, we provide the latest updates on wastewater-based epidemiology, which is gaining interest in the current situation as a unique tool of surveillance and monitoring of the disease. Transport pathways with its migration through wastewater to surface and subsurface waters, probability of infectivity and ways of inactivation of SARS-CoV-2 are discussed in detail. Epidemiological models, especially compartmental projections, have been explained with an emphasis on its limitation and the assumptions on which the future predictions of disease propagation are based. Besides, this review covers various predictive models to track and project disease spread in the future and gives an insight into the probability of a future outbreak of the disease.
\end{abstract}

Keywords SARS-CoV-2 $\cdot$ COVID-19 $\cdot$ Modelling $\cdot$ Wastewater $\cdot$ Monitoring

\section{Introduction}

The unprecedented event of COVID-19 pandemic brought by the novel coronavirus (SARS-CoV-2) with severe acute respiratory syndrome (SARS) has claimed more than 0.9 million lives across the globe. The novel coronavirus $(\mathrm{nCoV})$ belongs to the same subfamily of orthocoronavirinae as MERS-CoV

This article is part of the Topical Collection on Emerging Contaminants

Manish Kumar

manish.env@gmail.com; manish.kumar@iitgn.ac.in

1 Discipline of Earth Science, Indian Institute of Technology Gandhinagar, Room No. 336A, Block 5,

Gandhinagar, Gujarat 382355, India

2 Kiran C Patel Centre for Sustainable Development, Indian Institute of Technology Gandhinagar, Gandhinagar, Gujarat 382355, India

3 Environmnetal Science and Engineering Department, Indian Institute of Technology Bombay, Mumbai 400076, India

4 Centre for the Environment, Indian Institute of Technology Guwahati, Guwahati, Assam 781039, India

5 Discipline of Civil Engineering, Indian Institute of Technology Gandhinagar, Gandhinagar, Gujarat 382355, India and SARS-CoV. Still, it is distinctly disparate from the other members, in terms of its contagiousness and evolution rate [1-3]. While it is believed that infants and older people are more vulnerable to infection, young asymptomatic carriers are of significant concern as they aid in virus transmission without their knowledge [4]. Several reports have already documented the presence of the virus and its genetic material in the faecal matters

6 Faculty of Geosciences and Civil Engineering, Institute of Science and Engineering, Kanazawa University, Kanazawa 9201192, Japan

7 Faculty of Science, Engineering and Built Environment, Deakin University, Melbourne, Australia

8 School of Environment and Sustainable Development, Central University of Gujarat, Gandhinagar, Gujarat 382030, India

9 Department of Environmental Science, The Assam Royal Global University, Guwahati, Assam 781035, India

10 Center of Environmental Science, University of Allahabad, Prayagraj 211002, India

11 Ecosphere Resilience Research Centre, Faculty of Applied Sciences, University of Sri Jayewardenepura, Nugegoda, Sri Lanka

12 Department of Environmental and Civil Engineering, Toyama Prefectural University, Imizu 9390398, Japan 
and urine of infected persons. Additionally, several concerns have been raised, including possible leaching and infiltrations of effluents from health care facilities, sewage, and drainage water [5]. Thus, in this time of accelerated transmission of the novel coronavirus, it is crucial to have a robust surveillance system to pace the monitoring of the disease spread. Wastewater-based epidemiology (WBE) approach can be used to understand and evaluate the degree of establishment, penetrance, and infectivity of a specific infection in the community [6]. In this approach, presence and abundance of specific biomarkers (e.g. viral genes) in wastewater are examined, as they may reflect the general status of inhabitants related to the biomarkers within a given wastewater catchment [7]. This approach has proved useful for studying the epidemiology of various infectious diseases and is a crucial tool for disease prevention, control and intervention. Thus, this paper reviews the potential of WBE in establishing a vigilant and robust surveillance system to track down coronavirus spread in the community.

Although SARS viruses are of zoonotic origin and several countries have already facing secondary transmission of SARSCOV-2, developing an early warning system always presents a challenge. In addition to WBE, several modelling approaches might aid in assessing the disease spread both at a regional and global scale. While compartmental models have traditionally relied on the researcher's understanding of human behaviour but its relevance deteriorates as a function of limited understanding about the response of the government and knowledge about the virus as depicted in Fig. 1. Thus, statistical models have found its relevance at the wrong time as evident from the recent studies that advocated using Bacillus Calmette-Guérin (BCG) and Polio vaccination to counter the health implication of COVID-19 based on a simple correlation of early COVID-19 mortality data of countries like Iran and India [8]. Though BCG or Polio vaccines were helpful, predictions solely based on correlation analysis may compromise the entire response system against the virus. A greater challenge lies in making a wider audience to understand the very foundation on which this assumptive theory of virus predictions is based. Our aim through this article is to simplify these complex models into understandable theories so that the conclusions of the various prediction models may be understood in its context. This paper aims to collate information on recent developments on WBE in monitoring the trend of community-scale SARS-CoV-2 prevalence as well as models to predict virus spread and transmission among populations.

\section{Transmission, Infectivity and Inactivation of SARS-CoV-2}

\section{Faecal-Oral Route of SARS-CoV-2 Transmission}

The receptor-binding domain (RBD) of the heavily glycosylated S protein of SARS-CoV-2 interacts with the angiotensin- converting enzyme 2 (ACE2) receptor and attaches to the surface of the host cells leading to receptor-mediated endocytosis of the virion [9]. The viral envelope fuses with the endosomal membrane with the help of host proteases and releases the viral genome into the cytoplasm of the host cell [10]. The virus generally binds with ACE2 receptors in the lungs and intestinal tract, replicates further, resulting in severe consequences. More than $10 \%$ of patients without acute infection experienced diarrhoea and nausea within 1-2 days before the advancement of disease and development of any critical symptoms, including fever and respiratory illness [11-13]. Subsequently, it put forward the possibility of the virus load along with faecal matter either in an active or infective state.

This was later confirmed by the presence of the infectious virus and its genetic material (RNA) in the faecal matter of several patients infected by SARS-CoV-2 [14]. The RNA was continuously detected in the faecal matter of more than $23 \%$ of patients ages that ranged from 10 months to 78 years old [15]. During the infamous SARS (2002-03) and MERS (2012) outbreak, patients were suffered from several gastrointestinal symptoms, including diarrhoea at the beginning of the disease $[16,17]$. It has been reported that $16-73 \%$ of patients with SARS had diarrhoea throughout the malady, for the most part during the first week of the disease outbreak and the viral RNA continued to be found in the faecal matter of the patients even after 30 days of illness [17, 18]. As the disease progressed, MERS-CoV RNA was also detected in the faecal matter of most of the positive patients attributed to replication in human primary intestinal epithelial cells $[19,20]$. While the binding ability of ACE2 receptors decides the infectivity of SARS-CoV, SARS-CoV-2 was found to use human ACE2 at a better efficiency compared to other strains of SARS-CoV, including the strain identified in the year 2003 [21].

Although several recent publications have highlighted the presence of SARS-CoV-2 genetic materials [22-27] until today, there is no evidence of faecal-oral transmission of SARS CoV-2. However, presence of virus genetic material in toilet bowls, sinks, saliva and respiratory secretions of infected patients $[28,29]$ and the raw sewage water in different parts of the globe [22-27] has raised several concerns including enteric involvement of this virus. Available evidence on other SARS and MERS virus suggest that coronaviruses can survive for several weeks and retain its viability for several days at varying temperature range. It has been reported for SARS$\mathrm{CoV}$ where the virus remained viable for 5 days at a temperature ranging from 22 to $25^{\circ} \mathrm{C}$ and relative humidity ranging from 40 to $50 \%$ [30]. Interestingly, the same virus remained infectious for 2 weeks when the experiment was conducted for $4{ }^{\circ} \mathrm{C}$, but its infectivity reduced drastically to 2 days when the temperature was increased from 4 to $20^{\circ} \mathrm{C}$ [31]. Similarly, a recent study on the SARS-CoV-2 highlighted the computational modelling to study the travel time and survival of the virus from source to wastewater treatment plants (WWTPs) 
Fig. 1 Making waves perspectives of COVID-19 pandemic: monitoring, modelling, myth and mental health

\section{C淟VID-19 †ve}

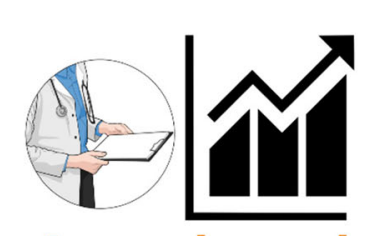

Increased research
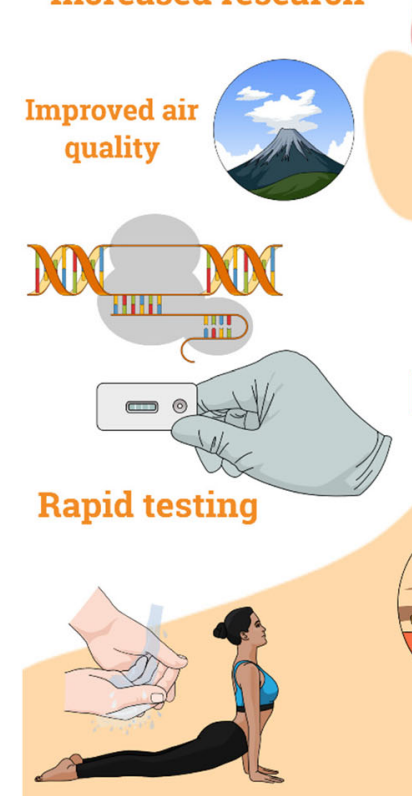

Increased hygeine and health consciousness

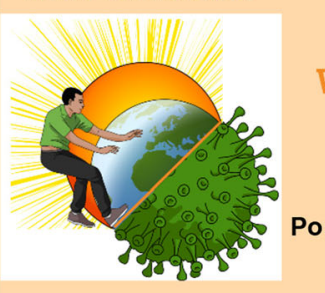

Functional Areas of the Brain

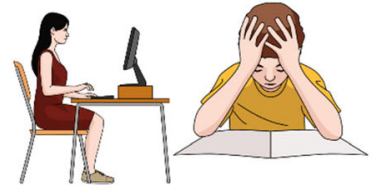

Work from home

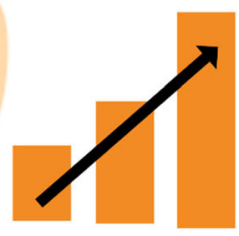

No of suicides and domestic violence cases
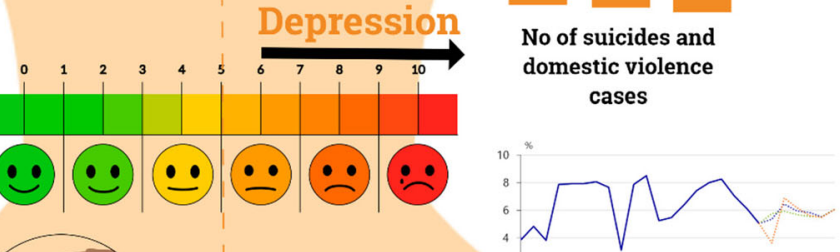
${ }_{4}^{6} \sim$
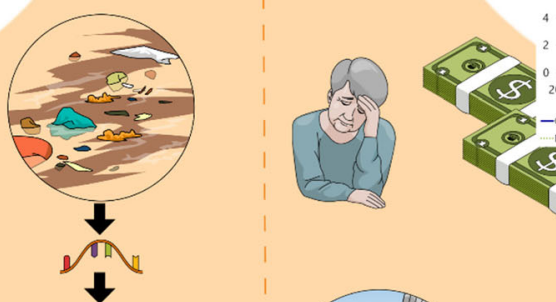

$\begin{array}{lllllll}0 & 1 & 1 & 1 & 1 \\ 2000 & 2004 & 2008 & 2012 & 2015 & 2020 & 2024\end{array}$

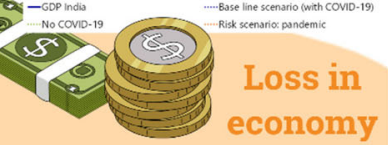

$\downarrow$

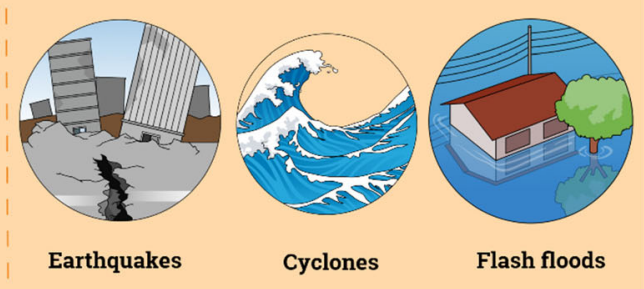

Post COVID-19 world | Natural disasters
[32]. Considering the proof of faecal discharge for both SARS-CoV and MERS-CoV and their capacity to stay viable under conditions that could encourage faecal-oral transmission, it is conceivable that SARS-CoV-2 could likewise be transmitted by means of this course. Thus, the enteric involvement of SARS-CoV-2 is of greater concern in developing and underdeveloped countries where poor hygiene practices and open defection are prevalent.

\section{Infectivity of SARS-CoV-2}

Several techniques have been developed to detect viruses and their genetic material in various environmental matrices. In general, while some techniques test infectivity of viruses, others focused on nucleic acid isolation. Most of the approaches to detect and diagnose SARS-CoV-2 are based on the isolation of genetic material of the virus to confirm infection among patients (Fig. 2). However, over the past, techniques such as cell culture and PCR-based molecular techniques have been used $[33,34]$. Cell culture assays investigate both virus presence and its infectivity by monitoring response (cytopathic effects, cells bursting, plaque) of suitable host cells. However, the difficulty of culturing and slow growth rates discourages the application of this method specifically to the novel virus, where expensive cell culture assay and requirement of biosafety level 3 are of additional concern. Recently, many researchers have reported the presence of SARS-CoV-2 RNA in the wastewater using reverse transcriptase-PCR (RT-PCR) technique. This technique involves RNA concentration, extraction, amplification to detect 


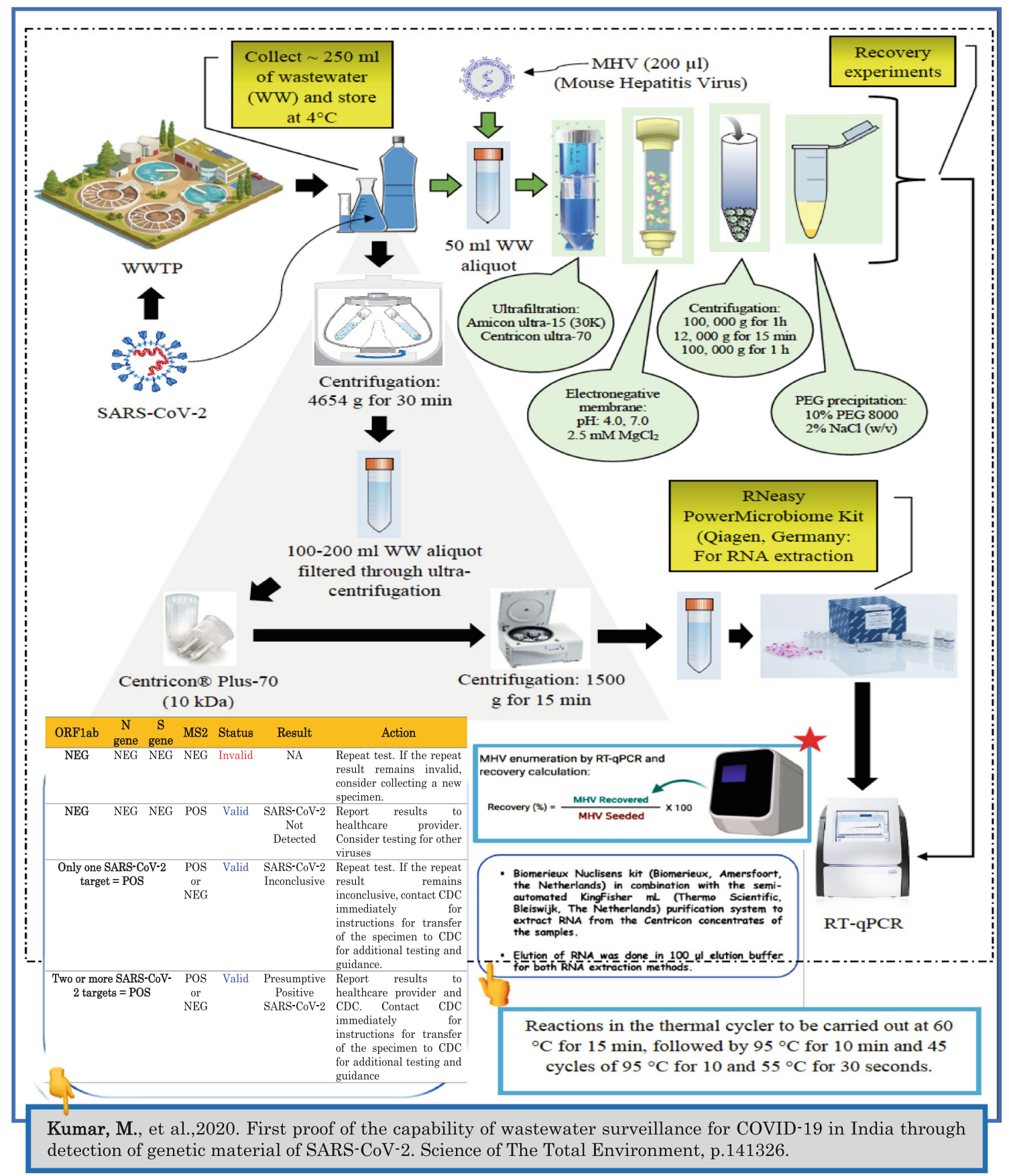

Fig. 2 Extraction and analysis protocol of SARS-CoV-2 (adopted from Ahmed et al. (2020b), Kumar et al. (2020) and Medema et al. (2020))

its presence at the lowest available concentration without giving much information on the infectious nature of the virus. There is much discussion around the infectious nature of SARS-COV-2 and the role of its genetic material.

However, SARS-CoV-2 needs much more than its genetic material to spread infections. Outside the host, the virus is considered to be non-living, i.e. viron, which is mainly composed of RNA, surrounded by a lipid envelop and cannot selfreplicate. Infection is only possible due to the presence of viable virus but not due to the presence of its genetic material in the host body. The virus is said to be viable if it replicates and increases the viral load in the host body. SARS-CoV-2 through its spike proteins (S protein) attach to the host cell receptors (ACE2), which is commonly found in the respiratory or intestinal tract of human beings and subsequently enters into the host cell to replicate [10]. As PCR targets specific parts of the virus genetic material, the degree to which a virus was affected by several disinfectants present in the wastewater and its viability cannot be addressed by this technique. Hence, the detection of SARS-CoV-2 RNA does not imply the 
infectious nature of the virus. Therefore, assay-based techniques are more appropriate to study the infectious nature of the virus.

\section{Inactivation of SARS-CoV-2 and Its Genetic Materials During Chlorination at WTPs and WWTPs}

While several studies have identified the presence of SARS-CoV-2 in the faecal matter of corona-infected patients $[35,36]$, there is a growing concern on the transmission of the virus through water treatment plants (WTPs) and WWTPs. Several studies also detected the genetic material of the virus in raw wastewater across the globe [22, $26,27]$. Nevertheless, the viability and infectivity of the virus in faecal matter are yet to be documented; the possibility of virus transmission through wastewater and drinking water is of major concern. Previous studies have highlighted the persistence of coronavirus and SARS virus in the wastewater, which ranged from hours to several days in the absence of disinfection practices [31, 37]. Chlorination is the most commonly used disinfection technique, mainly in both WTPs and WWTPs in developed and developing countries as a tertiary treatment step [38]. Although the effect of chlorine on disinfection of SARS$\mathrm{CoV}-2$ has not yet been documented, available data on other enveloped and coronaviruses can provide an insight into the viability and infectious nature of viruses. Chlorination was found to be effective against several enveloped viruses, such as vesicular stomatitis virus, African swine fever virus, equine viral arteritis virus and porcine reproductive and respiratory syndrome virus within $10 \mathrm{~min}$ of exposure [39].

Among the enveloped viruses, equine viral arteritis virus was inactivated $100 \%$ when exposed to chlorine $(0.015 \%)$ for $1 \mathrm{~min}$. Similarly, SARS was reported to be disinfected adequately at a free chlorine dose ranging from 0.2 to $0.5 \mathrm{mg} / \mathrm{L}$ [31]. Another enveloped virus, Ebola, was reported to be disinfected $100 \%$ at chlorine doses of 5 and $10 \mathrm{mg} / \mathrm{L}$, and a $3.5 \log _{10}$ reduction was reported in the presence of free residual chlorine $0.16 \mathrm{mg} / \mathrm{L}$ under $20 \mathrm{~s}$ contact time [40]. Free chlorine is known to penetrate the membrane of modelled enveloped virus (Pseudomonas phage Phi6) and reacted rapidly with the proteins and polymerase complex. Instead, the peptides of the enveloped virus are 150 times more reactive than the studied non-enveloped coliphage MS2 virus. In such a scenario, inactivation of the order $4 \log _{10}$ was reported for Phi6 [41]. Recently, acidic electrolyzed water (EW) having a high concentration of free available chlorine has shown strong potential in deactivating SARS-CoV-2. It was found that virucidal activity of the virus significantly increased with the loss of free chlorine at long residence time [42]. Hence, the risk of SARS-CoV-2 transmission through drinking water and wastewater is low where chlorination is carried out as it is expected to inactivate the virus and its genetic materials, which has been seen for other enveloped viruses. However, community exposure through sewage overflow, building having a faulty plumbing system [43] or aerosol-mode transmission at the WWTPs [44] cannot be avoided.

\section{Perspectives of Wastewater-Based Epidemiology: Monitoring COVID-19}

WHO has highlighted that since 1970s, over 1500 novel pathogens have been discovered and close to 40 new transmittable diseases were identified [17]. Most of these diseases were reported to have a severe impact at the community level, with reports of many outbreaks happening during the last 20 years, most significantly SARS (severe acute respiratory syndrome) during 2002-2003 and COVID-19 during 2019-2020 [17]. The consequences of such an epidemic/pandemic have led to the emergence of critical monitoring on the spread and the disease trend. However, there exist various limitations in the surveillance systems mainly to cope with the rapid population growth and changing environmental conditions.

Wastewater-based-epidemiology (WBE) approach could be applied as a monitoring tool for surveillance and early warning systems of transmittable disease hotspots (Fig. 3). According to recent reports [35, 45], SARS-CoV-2 was shed in the patients' faecal matter for much longer (e.g. 22 days) than the duration of virus shedding in the upper respiratory swabs (10 days). Hence, identification and quantification of the viral genome in wastewater can be a reliable indicator of disease prevalence among the communities, as revealed for other similar viruses [46-48]. Very recently, studies report detections of RNA of SARS-CoV-2 in wastewater [27, 46, 49-53], with detected RNA amount being higher than that expected from reported infection cases. Moreover, SARSCoV-2 was detected in wastewater 7-10 days earlier than clinically reported cases [46, 53, 54]. In summary, wastewater analysis is recommended as a non-invasive initial-warning tool that can help in monitoring the trend and status of COVID-19 spread and as a device for tweaking public health response $[35,55,56]$. Thus, under the present condition, such environmental surveillance tool also has the potential to be implemented in wastewater treatment systems to help authorities to manage/regulate the exit strategy.

\section{Predictive Models}

Earlier knowledge regarding 2019-nCoV hinted at transmission being limited between animals and humans, with lesser development and emphasis in terms of inter-human transmission, making earlier epidemiological predictions $[57,58]$. Recent developments in terms of phylogenesis, 


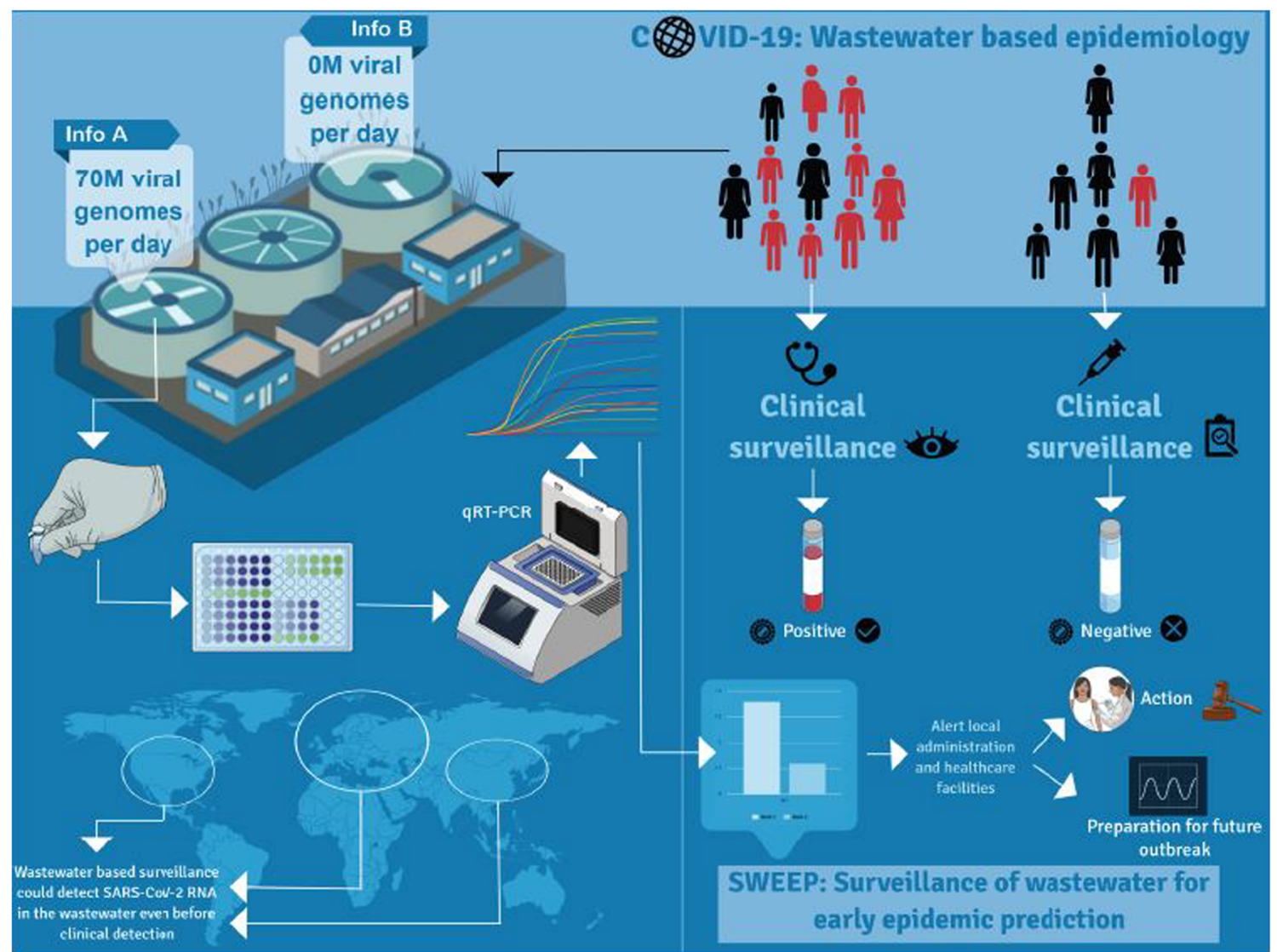

Fig. 3 Wastewater-based epidemiology and monitoring of SARS-COV-2

molecular epidemiology and refinements in evolutionary models have helped build a broader understanding of the spread and transmission of the current pandemic [59]. Phylogenetic evolution can be traced and validated using different mathematical models, primarily aimed at the detection of episodic mutating diversification and pervasive selection, including techniques of projection-based fitting of nucleotide substitution [60]. Further, homology models, enabling protein structures to be analysed and compared in a three-dimensional space, provide higher leverage for understanding the structural templates [61].

However, a serious shortcoming in various risk-based projection models is with regards to its predictability of spread of infection, which considerably and dynamically change in response to the social behaviour of the people under time accelerated learning model [62]. This void creates a large scope for the induction of pure statistics-based mathematical models with various epidemiological considerations taking a back seat and so is the accuracy and precision of the prediction. Therefore, with regard to the stated facts, we have reviewed the historical, mathematical, epidemiological evolution of various models with regards to their capabilities in early detection of (i) disease spread, (ii) co-variability of the virus with environmental factors and (iii) transmission among and between different multi-cellular species.

\section{Disease Spread}

The potential scale of the spread of a virus can be understood in terms of its basic reproduction number $\left(R_{\mathrm{o}}\right)$. However, studies show that $R_{\mathrm{o}}$ variability with societal intervention is more severe than previously assumed, as has been the case in Wuhan, China, where $R_{\mathrm{o}}$ declined to 0.32 from 3.86 post-implementation of lockdown $[62,63]$. These models often referred to as compartmental models, segregate the population into various broad categories such as (i) susceptible (S), exposed (E), infectious (I) and recovered (R). It has gained widespread popularity in the field of epidemic spread due to its greater mathematical emphasis on simulating and adapting under real conditions. Most of these epidemiological models trace their origin in the theory of [64] Kermack and McKendrick (1927) and the early works of Ross and Hudson [65], which stressed on finding the critical causal factor which impacts the severity and frequency of the epidemic. In this regard, a brief overview of their work becomes essential in understanding the assumptions as well as the accuracy of these models. Kermack and McKendrick formulated a simple hypothesis and opined that epidemics propagates in the community via direct contact with an infected person, while other indirect transmission sources being negligible. 
With the rapid spread of infection, the number of sick people in the population increases, which further stabilizes on account of increasing deaths and recoveries. Also, the chances and prospects of recovery or death or future infection to other persons will change with each passing day in the infection cycle of a sick person. A primary assumption of the theory was that epidemics are usually short-lived, and therefore, cannot change the population at large. Thus, the community under scrutiny for disease spread was kept constant for modelling. The study established that for each set of recovery, death and infectivity, there exists a threshold population density. If the current population of the region exceeds the threshold density, then any addition of a newly infected case will result in the start of the epidemic cycle again. A serious observation was concerning predicting the end of the epidemic. Kermack and McKendrick believed that infection exists in a region as long as its population exceeds the critical population density with the epidemic trying hard to move the community towards the critical threshold value, where it finally wanes away and dies out. The theory was further modified to compare the virulence and severity of different viruses for the population with identical population density, recovery and death rate. To give a mathematical basis to this developed hypothesis, the two researchers divided the time into a large number of small constant units, with the assumption that infection starts at the beginning of the time instant with no occurrence of any outbreak in between the passage of one-time unit to other (eq. 1).

$Y_{t}, \theta=\sum_{\theta=0}^{t} P_{t}, \theta$

Here, $t$ means the time and $\theta$ means the total number of time intervals. $Y_{\mathrm{t}, \theta}$ shows the total sick population and $P_{\mathrm{t}, \theta}$ denotes the infected people at any given time instant. $P_{0,0}$ will indicate the total infected population at the beginning of the modelling, including the newly infected as well as the existing infected people, which are the potential host for the epidemic spread in the population. If we assume the rate of removal as $\Psi$ (sum of recovery and death rate), then the total removed population from the consideration will be $\Psi_{\theta} Y_{\mathrm{t}, \theta}$, which is equal to $Y_{\mathrm{t}, \theta}-Y_{\mathrm{t}+1, \theta+1}$. Further, if we assume the rate of infectivity to be $\phi_{\theta}$ after the passage of $\theta$ time intervals and the total unaffected population to be $x_{\mathrm{t}}$, then the total number of people becoming infected in the unit area as a function of unaffected people will be given by eq. 2 .

$P_{t}=x_{t} \sum_{1}^{t} \phi \theta P_{t}, \theta$

Further simplifications lead to the expression of these terms in a more complex differential form, drawing heavily upon the concepts of infinite integrations, which are beyond the scope of this review. However, a more straightforward but more accurate modified form of the current model was used by
$[62,63]$, for evaluating the coronavirus spread in Wuhan, China. The study divided the population of Wuhan into six categories, including Susceptible (S), Latent (E), Reported Infectious (I), Unreported Infectious (A), Hospitalized (H) and Recovered (R). Further, two key parameters, including transmission rate $(b)$ and ascertainment rate $(r)$, were used to develop a dynamic network of parameters, which could be represented by eq. 3 .

$\frac{d R}{d t}=\frac{I+A}{D i}+\frac{H}{D h}+\frac{n R}{N-I-H}$

where Di and Dh are the infection and hospitalization period, respectively. Further, the effective reproduction number of the disease was calculated as per eq. 4

$R t=\frac{D i b}{A+I}\left(\alpha A+\frac{D q I}{D i+D q}\right)$

where $\alpha$ is the rate of transmission calculated as the ratio of unascertained vs. ascertained cases and Dq is the period from the onset of symptoms of illness to the hospitalization time. Further, the distribution parameters were estimated using Monte-Carlo Markov chain (MCMC) simulations using the likelihood and Poisson distribution functions.

The same model was also used by [66] in predicting the $R_{\mathrm{o}}$ of 2019-nCoV to be around 2.68. More so, the baseline projection of the study estimated that the mean imported infectious cases in the cities of Beijing, Shanghai and Shenzhen could be 113, 98 and 80, respectively. [67] employed similar compartmental models to divide the population of Hubei province into 5 categories, including susceptible population, asymptomatic, infectious with symptoms, isolated, and recovered to estimate a $R_{\mathrm{o}}$ value of 6.49 . The most conservative estimate of $\mathrm{R}_{\mathrm{o}}$ for China has been from WHO, which predicted value between 1.4 and 2.5. [68] used an additional two categories of death and cumulative cases to estimate a $R_{\mathrm{o}}$ of 4.08 , assuming an average latent period of infection to be 9 days. [69] overestimated the $R_{\mathrm{o}}$ value for China to be 6.47 , despite being based on the compartmental models and including appropriate social interventions. While these epidemiological models are more flexible in terms of incorporating dynamic changes with regards to the spread of the virus, their variability in prediction has led to increased dependency of researchers on statistical trend-based models. In this regard, the study by [70] used a simple statistical growth function with an assumed incubation and serial interval of 5.2 and 7.5 days, respectively.

Similarly, [71] used outbreak trajectories from stochastic simulations to obtain a $R_{\mathrm{O}}$ value of 2.2. [72] used a more precise estimation method involving epidemiological data concerning hospitalization, death and onset of illness. Further, through a doubly interval-censored likelihood function and Bayesian methods, different parameter values within 
the intervals were determined. Statistical models have also been used in order to estimate the serial interval (time duration between two successive cases in an epidemiological transmission chain) of $\mathrm{nCoV}$ using a similar Bayesian approach [73]. Few studies have relied on fitting data in different probability density functions to estimate the incubation period of 2019$\mathrm{nCoV}$ to be around 5.1 days [74].

\section{Effect of Environmental Factors}

Associating environmental conditions with the spread of 2019-nCoV started due to some early work on SARS-CoV, where it was found that out of the four protein structures of the SARS-CoV, i.e. (i) Spike protein (S), (ii) Nucleocapsid (N), (iii) Envelope protein (E) and (iv) Membrane protein (M), the $\mathrm{N}$ protein exhibits the highest hydrophilicity and least stability due to absence of disulphide bonds. The high isoelectric point $(\mathrm{pI}=10.1)$ and the absence of cysteine residue, makes N protein the weakest link of the virus [75]. Any disruption in the $\mathrm{N}$ protein means inhibition in the replication of viral RNA. Further, the sub-genomic transcription and translation also suffer, leading to instability of the virus. Earlier studies by [76], suggested that the poliovirus and rhinovirus have also suffered a similar fate due to viral capsid inactivation at $42^{\circ}-$ $45^{\circ} \mathrm{C}$ following the denaturation of protein structures. A study by Jane-Valbuena et al. [77] further showed that the few outer capsid proteins are highly thermal sensitive. These studies provided enough excellent reasons for modelling the spread of 2019-nCoV with the external environmental conditions, assuming that the cases of infection will decrease through secondary infection routes due to the inactivation of the virus on different surfaces; however, the possibility of transmission via direct contact remains unchanged.

While the 2019-nCov transmission rate is directly dependent upon close contact with the infected person but the possibility of aerosol suspension via droplets from contagious people remains a significant source of secondary infection. A study by [78] showed that some known coronavirus (HCV/229E) could survive and attain a half-life between 27 and $67 \mathrm{~h}$ in conditions with humidity varying between 30 and $50 \%$. Further evidence suggests that a decrease in temperature by $6{ }^{\circ} \mathrm{C}$ can increase the half-life of the virus by $3 \mathrm{~h}$, even at $80 \%$ humidity [79]. An interesting observation in this regard was noted in SARS outbreak, where it was suggested that due to the low humidity conditions inside the airplane, the virus reached beyond $2 \mathrm{~m}$ from the infected person [80]. It is worth noting that all the previous studies have explicitly pointed to the role of humidity and air temperature as the controlling variables in virus spread. However, the consensus is still not clear about the magnitude to which these variables impact the virus spread. Published articles have stated that warmer weathers have a suppressing impact on the contagion spread, but the previous outbreak never happened to the scale that has occurred in 2019-2020, leaving lesser applicability of the inferences of these researches [81-84]. We have presented the various modelling studies done in this regard in Table 1.

\section{Transmission}

The spread of coronavirus is sporadic through human-tohuman transmission mainly by droplets produced during coughing or sneezing. There are two pathways involved in transmission one via direct contact with the symptomatic patient and another is indirect contact from the environment [92]. Direct contact with symptomatic patient implies being in close proximity with COVID-19-infected patient that is within the periphery of $1 \mathrm{~m}$. On the other hand, indirect contact happens via the presence of microbes within droplet nuclei (i.e., particle $<5 \mu \mathrm{m}$ diameter) in the air or over surfaces $[35,36]$. These droplet nuclei can survive in the air or on surfaces for a longer period and, therefore, can be transmitted by coming in contact with an infected surface. However, the probability of airborne transfer is dependent upon the retention power of droplet nuclei in the air or on the surfaces. The likelihood of indirect transmission is less likely in comparison to direct transmission. Further, there has been some evidence suggesting oral-faecal transmission of the virus as COVID-19 infects the intestinal tract, thereby indicating the faecal presence of the virus [93-99]. However, this paper, as mentioned above, rules out any such established possibility as of now. Based on the available evidence, the WHO has recommended the use of masks to avoid direct and indirect transmission of the virus.

\section{Conclusions}

The impact of the coronavirus pandemic is devastating. It has raised several concerns among the population due to fear and worries of catching an infection. Although several enveloped viruses are reports to survive for many days, even at $25^{\circ} \mathrm{C}$, countries with hot weather have reported cases of COVID-19. Several factors, including virus transmission, infectivity and inactivation, are crucial before assessing WBE. This review raised the concern on the faecal-oral route of virus transmission, especially in developing countries lacking disinfection steps in water and wastewater treatment plants. Additionally, countries lacking proper sanitation facilities having open defecation practices are more vulnerable to be infected by SARS$\mathrm{CoV}-2$. The high variance in the prediction capability of various statistical models proves less beneficial for government authorities in dealing with the containment of the disease spread. However, the compartmental models can offer higher adaptability under these circumstances and can offer higher leverage in terms of policy planning. 


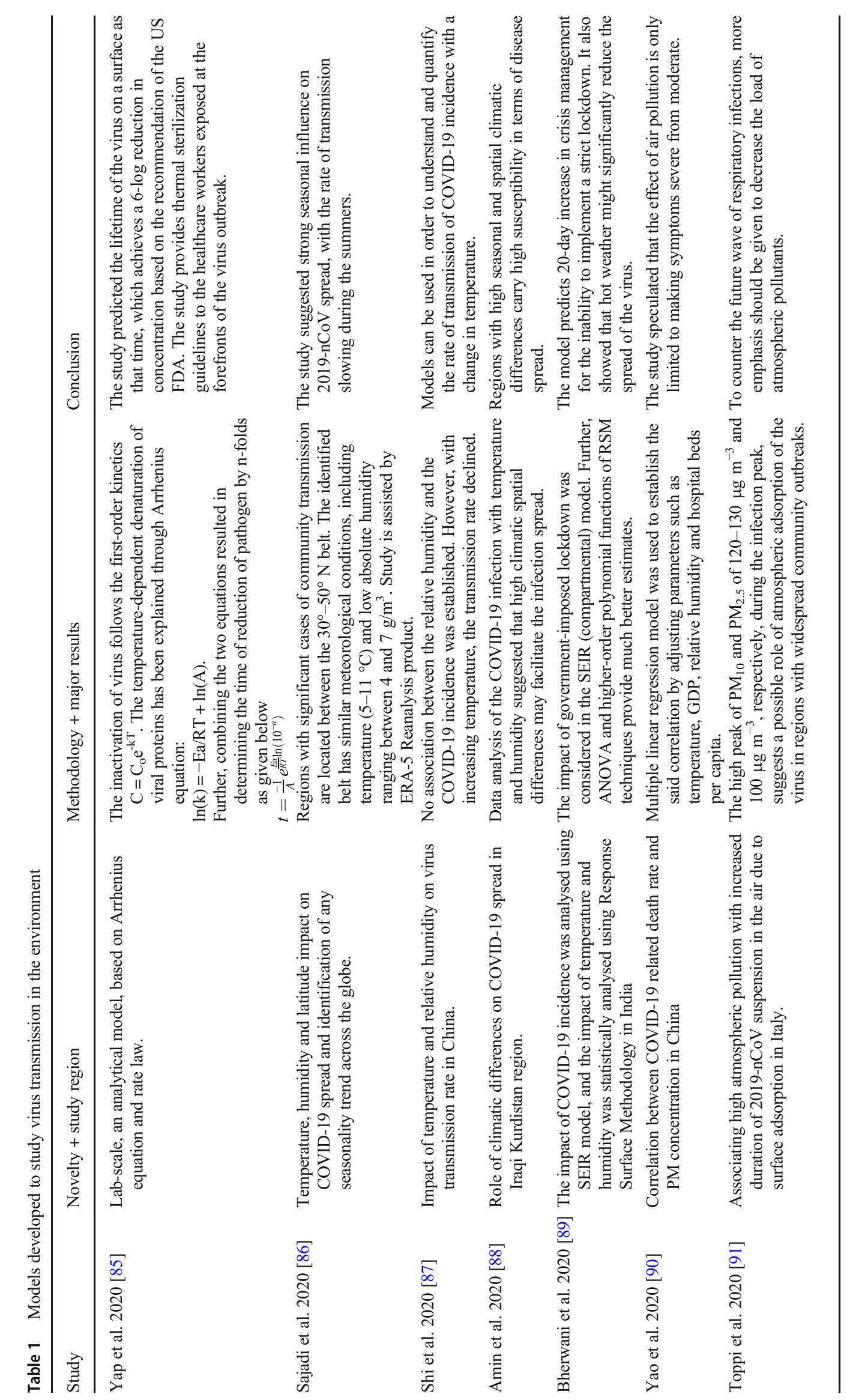


Acknowledgments We acknowledge the fund received from Kiran C Patel Centre for Sustainable Development (KPCSD) and UK-India Education and Research Initiative (UKIERI).

\section{Compliance with Ethical Standards}

Conflict of Interest The authors declare that they have no conflict of interest.

Human and Animal Rights and Informed Consent This article does not contain any studies with human or animal subjects performed by any of the authors.

\section{References}

Papers of particular interest, published recently, have been highlighted as:

- Of importance

•- Of major importance

1. Zhu N, Zhang D, Wang W, Li X, Yang B, Song J, et al. A novel coronavirus from patients with pneumonia in China, 2019. N Engl J Med 2020

2. Kumar M, Patel AK, Shah AV, Raval J, Rajpara N, Joshi M, et al. First proof of the capability of wastewater surveillance for COVID19 in India through detection of genetic material of SARS-CoV-2. Sci Total Environ 2020;141326.

3. Kumar M, Taki K, Gahlot R, Sharma A, Dhangar K. A chronicle of SARS-CoV-2: part-I-epidemiology, diagnosis, prognosis, transmission and treatment. Sci Total Environ 2020;139278.

4. van der Voorn T, van den Berg C, Bhattacharya P, Quist J. Never waste a crisis: drawing first lessons from the COVID-19 pandemic to tackle the water crisis. ACS ES\&T Water 2020

5. Kumar M, Thakur AK, Mazumder P, Kuroda K, Mohapatra S, Rinklebe J, et al. Frontier review on the propensity and repercussionof SARS-CoV-2 migration to aquatic environment. J Hazard Mater Letters. 2020. https://doi.org/10.1016/j.hazl.2020. 100001.

6. Choi PM, Tscharke BJ, Donner E, O’Brien JW, Grant SC, Kaserzon SL, et al. Wastewater-based epidemiology biomarkers: past, present and future. TrAC Trends Anal Chem. 2018;105:45369.

7. Sims N, Kasprzyk-Hordern B. Future perspectives of wastewaterbased epidemiology: monitoring infectious disease spread and resistance to the community level. Environ Int 2020;105689.

8. Miller A, Reandelar MJ, Fasciglione K, Roumenova V, Li Y, Otazu GH. Correlation between universal BCG vaccination policy and reduced morbidity and mortality for COVID-19: an epidemiological study. MedRxiv. 2020

9. Wrapp D, Wang N, Corbett KS, Goldsmith JA, Hsieh C-L, Abiona O, et al. Cryo-EM structure of the 2019-nCoV spike in the prefusion conformation. Science. 2020;367(6483):1260-3.

10. Bosch BJ, Van der Zee R, De Haan CA, Rottier PJ. The coronavirus spike protein is a class I virus fusion protein: structural and functional characterization of the fusion core complex. J Virol. 2003;77(16):8801-11.

11. Chen N, Zhou M, Dong X, Qu J, Gong F, Han Y, et al. Epidemiological and clinical characteristics of 99 cases of 2019 novel coronavirus pneumonia in Wuhan, China: a descriptive study. Lancet. 2020;395(10223):507-13.
12. Huang C, Wang Y, Li X, Ren L, Zhao J, Hu Y, et al. Clinical features of patients infected with 2019 novel coronavirus in Wuhan. China The Lancet. 2020;395(10223):497-506.

13. Wang D, Hu B, Hu C, Zhu F, Liu X, Zhang J, et al. Clinical characteristics of 138 hospitalized patients with 2019 novel coronavirus-infected pneumonia in Wuhan, China. JAMA Journal of the American Medical Association. 2020;323:1061.

14. Xu Y, Li X, Zhu B, Liang H, Fang C, Gong Y, et al. Characteristics of pediatric SARS-CoV-2 infection and potential evidence for persistent fecal viral shedding. Nat Med. 2020;26:502-5.

15. Xiao F, Tang M, Zheng X, Liu Y, Li X, Shan H. Evidence for gastrointestinal infection of SARS-CoV-2. Gastroenterology. 2020;1-3.

16. Assiri A, Al-Tawfiq JA, Al-Rabeeah AA, Al-Rabiah FA, Al-Hajjar S, Al-Barrak A, et al. Epidemiological, demographic, and clinical characteristics of 47 cases of Middle East respiratory syndrome coronavirus disease from Saudi Arabia: a descriptive study. Lancet Infect Dis. 2013;13:752-61.

17. WHO. WHO issues consensus document on the epidemiology of SARS. Wkly Epidemiol Rec. 2003;78:373-5.

18. Chan KH, Poon LLLM, Cheng VCC, Guan Y, Hung IFN, Kong J, et al. Detection of SARS coronavirus in patients with suspected SARS. Emerging Infectious Diseases. 2004

19. Corman VM, Albarrak AM, Omrani AS, Albarrak MM, Farah ME, Almasri M, et al. Viral shedding and antibody response in $37 \mathrm{pa}-$ tients with Middle East respiratory syndrome coronavirus infection. Clin Infect Dis. 2015:civ951.

20. Zhou J, Li C, Zhao G, Chu H, Wang D, Yan HHN, et al. Human intestinal tract serves as an alternative infection route for Middle East respiratory syndrome coronavirus. Science Advances. 2017;3(11).

21. Wan Y, Shang J, Graham R, Baric RS, Li F. Receptor recognition by novel coronavirus from Wuhan: an analysis based on decadelong structural studies of SARS. Journal of Virology. 2020;(March):1-9.

22. Ahmed W, Angel N, Edson J, Bibby K, Brien JWO, Choi PM, et al. First confirmed detection of SARS-CoV-2 in untreated wastewater in Australia: a proof of concept for the wastewater surveillance of COVID-19 in the community. Sci Total Environ. 2020;78:138764.

23. Wu F, Xiao A, Zhang J, Gu X, Lee W, Kauffman K, et al. SARSCoV-2 titers in wastewater are higher than expected from clinically confirmed cases. medRixiv. 2020;(February 2019):1-13.

24. Medema G, Heijnen L, Elsinga G, Italiaander R, Medema G. Presence of SARS-coronavirus-2 in sewage. medRxiv. 2020

25. Kitajima M, Ahmed W, Bibby K, Gerba CP, Hamilton KA, Haramoto E, et al. SARS-CoV-2 in wastewater: state of the knowledge and research needs. Sci Total Environ 2020;139076.

26. Nemudryi A, Nemudraia A, Surya K, Wiegand T, Buyukyoruk M, Wilkinson R, et al. Temporal detection and phylogenetic assessment of SARS-CoV-2 in municipal wastewater. medRxiv. 2020;(3):1-9.

27. Wurtzer S, Marechal V, Jm M, Moulin L, Université S, Metis UMR, et al. Time course quantitative detection of SARS-CoV-2 in Parisian wastewaters correlates with COVID-19 confirmed cases. medRixiv. 2020

28. Gu J, Han B, Wang J. COVID-19: gastrointestinal manifestations and potential fecal-oral transmission. Gastroenterology. 2020;(April):118-9.

29. Yeo C, Kaushal S, Yeo D. Enteric involvement of coronaviruses: is faecal-oral transmission of SARS-CoV-2 possible? The Lancet Gastroenterology and Hepatology. 2020;5(4):335-7.

30. Chan KH, Peiris JSM, Lam SY, Poon LLM, Yuen KY, Seto WH. The effects of temperature and relative humidity on the viability of the SARS coronavirus. Advances in Virology. 2011;2011:1-7.

31. Wang XW, Li JS, Guo TK, Zhen B, Kong QX, Yi B, et al. Concentration and detection of SARS coronavirus in sewage from 
Xiao Tang Shan Hospital and the 309th Hospital. J Virol Methods. 2005;128(1-2):156-61.

32. Hart OE, Halden RU. Computational analysis of SARS-CoV-2/ COVID-19 surveillance by wastewater-based epidemiology locally and globally: feasibility, economy, opportunities and challenges. Sci Total Environ 2020;138875.

33. Atabakhsh P, Kargar M, Doosti A. Molecular surveillance of human rotaviruses in drinking water and investigation of the efficiency of their removal in Isfahan water treatment plant. Environmental Monitoring and Assessment. 2019;191(12).

34. Pimenta AI, Guerreiro D, Madureira J, Margaça FMA, Cabo VS. Tracking human adenovirus inactivation by gamma radiation under different environmental conditions. Appl Environ Microbiol. 2016;82(17):5166-73.

35. Chen Y, Chen L, Deng Q, Zhang G, Wu K, Ni L, et al. The presence of SARS-CoV-2 RNA in feces of COVID-19 patients. Journal of Medical Virology. 2020;(March).

36. Xing Y-H, Ni W, Wu Q, Li W-J, Li G-J, Wang W-D, et al. Prolonged viral shedding in feces of pediatric patients with coronavirus disease 2019. Journal of Microbiology, Immunology and Infection. 2020;(xxxx):1-8.

37. Casanova L, Rutala WA, Weber DJ, Sobsey MD. Survival of surrogate coronaviruses in water. Water Res. 2009;43(7):1893-8.

38. Mohapatra S, Sargaonkar A, Labhasetwar PK. Distribution network assessment using EPANET for intermittent and continuous water supply. Water Resources Management. 2014;

39. Shirai J, Kanno T, Tsuchiya Y, Mitsubayashi S, Seki R. Effects of chlorine, iodine, and quaternary ammonium compound disinfectants on several exotic disease viruses. J Vet Med Sci. 2000;62(1): 85-92.

40. Bibby K, Fischer RJ, Casson LW, Stachler E, Haas CN, Munster VJ. Persistence of ebola virus in sterilized wastewater. Environmental Science and Technology Letters. 2015;2(9):245-9.

41. Ye Y, Chang PH, Hartert J, Wigginton KR. Reactivity of enveloped virus genome, proteins, and lipids with free chlorine and UV 254. Envoronmental Science and Technology. 2018;52:7698-708.

42. Takeda Y, Uchiumi H, Matsuda S, Ogawa H. Acidic electrolyzed water potently inactivates SARS-CoV-2 depending on the amount of free available chlorine contacting with the virus. Biochem Biophys Res Commun. 2020;530:1-3.

43. Gormley M, Aspray TJ, Kelly DA. COVID-19: mitigating transmission via wastewater plumbing systems. Lancet Glob Health. 2020;20:30112.

44. Mcdermott C V, Alicic RZ, Harden N, Cox EJ, James M. Put a lid on it: are faecal bio-aerosols a route of transmission for SARSCoV-2? Journal of Hospital Infection. 2020;1-7.

45. Gupta S, Parker J, Smits S, Underwood J, Dolwani S. Persistent viral shedding of SARS-CoV-2 in faeces-a rapid review. Color Dis. 2020;22:611-20.

46. Hata A, Honda R, Hara-Yamamura H, Meuchi Y. Detection of SARS-CoV-2 in wastewater in Japan by multiple molecular assays-implication for wastewater-based epidemiology (WBE). medRxiv. 2020

47. Hata A, Honda R. Potential sensitivity of wastewater monitoring for SARS-CoV-2: comparison with norovirus cases. Environmental Science \& Technology. 2020;54:6451-2.

48. Wigginton KR, Ye Y, Ellenberg RM. Emerging investigators series: the source and fate of pandemic viruses in the urban water cycle. Environmental Science: Water Research \& Technology. 2015;1(6):735-46

49. Ahmed W, Angel N, Edson J, Bibby K, Bivins A, O'Brien JW, et al. First confirmed detection of SARS-CoV-2 in untreated wastewater in Australia: a proof of concept for the wastewater surveillance of COVID-19 in the community. Sci Total Environ $2020 ; 138764$.
50. La Rosa G, Iaconelli M, Mancini P, Ferraro GB, Veneri C, Bonadonna L, et al. First detection of SARS-CoV-2 in untreated wastewaters in Italy. Sci Total Environ 2020;139652.

51. Lodder W, de Roda Husman AM. SARS-CoV-2 in wastewater: potential health risk, but also data source. The Lancet Gastroenterology \& Hepatology. 2020;5(6):533-4.

52. Medema G, Heijnen L, Elsinga G, Italiaander R, Brouwer A. Presence of SARS-Coronavirus-2 in sewage. MedRxiv. 2020

53. Wurtzer S, Marechal V, Mouchel J-M, Moulin L. Time course quantitative detection of SARS-CoV-2 in Parisian wastewaters correlates with COVID-19 confirmed cases. MedRxiv. 2020

54. Peccia J, Zulli A, Brackney DE, Grubaugh ND, Kaplan EH, Casanovas-Massana A, et al. SARS-CoV-2 RNA concentrations in primary municipal sewage sludge as a leading indicator of COVID-19 outbreak dynamics. medRxiv. 2020

55. Daughton $\mathrm{C}$. The international imperative to rapidly and inexpensively monitor community-wide Covid-19 infection status and trends. The Science of the Total Environment. 2020;726:138149.

56. Naddeo V, Liu H. Editorial perspectives: 2019 novel coronavirus (SARS-CoV-2): what is its fate in urban water cycle and how can the water research community respond? Environmental Science: Water Research \& Technology. 2020;6(5):1213-6.

57. Lu R, Zhao X, Li J, Niu P, Yang B, Wu H, et al. Genomic characterisation and epidemiology of 2019 novel coronavirus: implications for virus origins and receptor binding. Lancet. 2020;395(10224):565-74.

58. Ji W, Wang W, Zhao X, Zai J, Li X. Cross-species transmission of the newly identified coronavirus 2019-nCoV. J Med Virol. 2020;92(4):433-40.

59. Benvenuto D, Giovanetti M, Ciccozzi A, Spoto S, Angeletti S, Ciccozzi M. The 2019-new coronavirus epidemic: evidence for virus evolution. J Med Virol. 2020;92(4):455-9.

60. Murrell B, Wertheim JO, Moola S, Weighill T, Scheffler K, Pond SLK. Detecting individual sites subject to episodic diversifying selection. PLoS Genet. 2012;8(7):e1002764.

61. Waterhouse A, Bertoni M, Bienert S, Studer G, Tauriello G, Gumienny R, et al. SWISS-MODEL: homology modelling of protein structures and complexes. Nucleic Acids Res. 2018;46(W1): W296-303.

62. Wang C, Liu L, Hao X, Guo H, Wang Q, Huang J, et al. Evolving epidemiology and impact of non-pharmaceutical interventions on the outbreak of coronavirus disease 2019 in Wuhan, China. MedRxiv. 2020

63. Wang D, Hu B, Hu C, Zhu F, Liu X, Zhang J, et al. Clinical characteristics of 138 hospitalized patients with 2019 novel coronavirus-infected pneumonia in Wuhan, China. Jama. 2020;323(11):1061-9.

64. Kermack WO, McKendrick AG. A contribution to the mathematical theory of epidemics. Proceedings of the royal society of london Series A, Containing papers of a mathematical and physical character. 1927;115(772):700-21.

65. Ross R, Hudson HP. An application of the theory of probabilities to the study of a priori pathometry. III Proc R Soc A. 1917;93:225-40

66. Wu F, Xiao A, Zhang J, Gu X, Lee WL, Kauffman K, et al. SARSCoV-2 titers in wastewater are higher than expected from clinically confirmed cases. medRxiv. 2020

67. Shen M, Peng Z, Xiao Y, Zhang L. Modelling the epidemic trend of the 2019 novel coronavirus outbreak in China. BioRxiv. 2020

68. Cao Z, Zhang Q, Lu X, Pfeiffer D, Jia Z, Song H, et al. Estimating the effective reproduction number of the $2019-\mathrm{nCoV}$ in China. MedRxiv. 2020

69. Tang B, Bragazzi NL, Li Q, Tang S, Xiao Y, Wu J. An updated estimation of the risk of transmission of the novel coronavirus (2019-nCov). Infectious disease modelling. 2020;5:248-55. 
70. Bai Y, Yao L, Wei T, Tian F, Jin D-Y, Chen L, et al. Presumed asymptomatic carrier transmission of COVID-19. Jama. 2020;323(14):1406-7.

71. Riou J, Althaus CL. Pattern of early human-to-human transmission of Wuhan 2019 novel coronavirus (2019-nCoV), December 2019 to January 2020. Eurosurveillance. 2020;25(4):2000058.

72. Linton NM, Kobayashi T, Yang Y, Hayashi K, Akhmetzhanov AR, Jung $\mathrm{S}$, et al. Incubation period and other epidemiological characteristics of 2019 novel coronavirus infections with right truncation: a statistical analysis of publicly available case data. J Clin Med. 2020;9(2):538.

73. Nishiura H, Jung S, Linton NM, Kinoshita R, Yang Y, Hayashi K, et al. The extent of transmission of novel coronavirus in Wuhan, China, 2020. Multidisciplinary Digital Publishing Institute; 2020.

74. Lauer SA, Grantz KH, Bi Q, Jones FK, Zheng Q, Meredith HR, et al. The incubation period of coronavirus disease 2019 (COVID19) from publicly reported confirmed cases: estimation and application. Ann Intern Med. 2020;172(9):577-82.

75. Wang Y, Wu X, Wang Y, Li B, Zhou H, Yuan G, et al. Low stability of nucleocapsid protein in SARS virus. Biochemistry. 2004;43(34):11103-8.

76. Dimmiock NJ. Differences between the thermal inactivation of picornaviruses at "high" and "low" temperatures. Virology. 1967;31(2):338-53.

77. Jane-Valbuena J, Nibert ML, Spencer SM, Walker SB, Baker TS, Chen Y, et al. Reovirus virion-like particles obtained by recoating infectiuos subvirion particles with baculovirus-expressed sigma 3 protein: an approach for analysing sigma 3 functions during virus entry. J Virol. 1999;73:2963-73.

78. Tang JW. The effect of environmental parameters on the survival of airborne infectious agents. Journal of the Royal Society Interface. 2009;6(suppl_6):S737-46.

79. Lowen AC, Steel J. Roles of humidity and temperature in shaping influenza seasonality. J Virol. 2014;88(14):7692-5.

80. La Rosa G, Fratini M, Libera SD, Iaconelli M, Muscillo M. Viral infections acquired indoors through airborne, droplet or contact transmission. Annali dell'Istituto superiore di sanita. 2013;49: 124-32.

81. Guo X-J, Zhang H, Zeng Y-P. Transmissibility of COVID-19 and its association with temperature and humidity. 2020

82. Berumen J, Schmulson M, Guerrero G, Barrera E, Larriva-Sahd J, Olaiz G, et al. Trends of SARS-Cov-2 infection in 67 countries: role of climate zone, temperature, humidity and curve behavior of cumulative frequency on duplication time. medRxiv. 2020

83. Qi H, Xiao S, Shi R, Ward MP, Chen Y, Tu W, et al. COVID-19 transmission in mainland China is associated with temperature and humidity: a time-series analysis. Sci Total Environ 2020;138778.

84. Islam N, Shabnam S, Erzurumluoglu AM (2020) Temperature,... Google Scholar [Internet]. [cited 2020 Aug 20]. Available from: https://scholar.google.com/scholar?hl=en\&as_sdt=0\%2C5\&q= Islam $+\mathrm{N} \% 2 \mathrm{C}+\mathrm{Shabnam}+\mathrm{S} \% 2 \mathrm{C}+$ Erzurumluoglu $+\mathrm{AM}+\%$ $282020 \% 29+$ Temperature $\% 2 \mathrm{C}+$ humidity $\% 2 \mathrm{C}+$ and +wind+ speed+are+associated+with+lower+Covid-19+incidence.+ medRxiv.+Preprint\&btnG=.

85. Yap TF, Liu Z, Shveda RA, Preston DJ. A predictive model of the temperature-dependent inactivation of coronaviruses. Appl Phys Lett. 2020;117(6):060601.

86. Sajadi MM, Habibzadeh P, Vintzileos A, Shokouhi S, MirallesWilhelm F, Amoroso A. Temperature and latitude analysis to predict potential spread and seasonality for COVID-19. Available at SSRN 3550308. 2020

87. Shi P, Dong Y, Yan H, Li X, Zhao C, Liu W, et al. The impact of temperature and absolute humidity on the coronavirus disease 2019 (COVID-19) outbreak-evidence from China. MedRxiv. 2020

88. Amin HNM, Amin HNM. Climate analysis to predict potential spread and seasonality for global (COVID-19) in Iraqi Kurdistan region. Kurdistan Journal of Applied Research. 2020:72-83.

89. Bherwani H, Gupta A, Anjum S, Anshul A, Kumar R. Exploring dependence of COVID-19 on environmental factors and spread prediction in India. 2020

90. Yao Y, Pan J, Wang W, Liu Z, Kan H, Qiu Y, et al. Association of particulate matter pollution and case fatality rate of COVID-19 in 49 Chinese cities. Sci Total Environ 2020;140396.

91. Sanità di Toppi L, Sanità di Toppi L, Bellini E. Novel coronavirus: how atmospheric particulate affects our environment and health. Challenges. 2020;11(1):6.

92. Holbrook MG, Amandine G, Williamson B, Tamin A, Harcourt J, Thornburg NJ, et al. Aerosol and surface stability of SARS-CoV-2 as compared with SARS-CoV-1. N Engl J Med 2020;0-2.

93. Bourouiba L. Turbulent gas clouds and respiratory pathogen emissions: potential implications for reducing transmission of COVID19. J Am Med Assoc 2020;E1-2.

94. Bivins A, North D, Ahmad A, Ahmed W, Alm E, Been F, et al. Wastewater-based epidemiology: global collaborative to maximize contributions in the fight against COVID-19. Environmental Science \& Technology. 2020;54:7754-7. https://doi.org/10.1021/ acs.est.0c02388.

95. Kumar M, Ram B, Honda R, Poopipattana C, Canh VD, Chaminda $\mathrm{T}$, et al. Concurrence of antibiotic resistant bacteria (ARB), viruses, pharmaceuticals and personal care products (PPCPs) in ambient waters of Guwahati, India: urban vulnerability and resilience perspective. Sci Total Environ. 2019;693:133640. https://doi.org/10. 1016/j.scitotenv.2019.133640.

96. Kumar, M., Chaminda, G. G. T., Honda, R. 2020. Seasonality impels the antibiotic resistance in Kelani River of the emerging economy of Sri Lanka. npj Clean Water 3, 12.

97. Kumar M, Kuroda K, Dhangar K, Mazumder P, Sonne C, Rinklebe $\mathrm{J}$, et al. Potential emergence of antiviral-resistant pandemic viruses via environmental drug exposure of animal reservoirs. Environmental Science \& Technology. 2020;54(14):8503-5. https://doi.org/10.1021/acs.est.0c03105.

98. Kumar, M., Kuroda, K., and Dhangar, K., 2020. The most eagerly awaited summer of the Anthropocene: a perspective of SARSCoV-2 decay and seasonal change. Groundwater of sustainable development. 100400. 11, 100400. https://doi.org/10.1016/j.gsd. 2020.100400 .

99. Kumar, M., Thakur, A., Mazumder, P., Kuroda, K., Mphaptra, S., Rinklebe, J., Ramanathan, AL., Cetecioglu, A., Jain, S., Tyagi, V., Gikas, P., Chakraborty, S., Islam, M.T., Ahmad, A., Shah, AV., Patel, A.K., Watanabe, T., Vithanage, M., Bibby, K., Kitajima, K., Bhattacharya, P. (2020). Frontier review on the propensity and repercussion of SARS-CoV-2 migration to aquatic environment. Hazardous Material Letters.

Publisher's Note Springer Nature remains neutral with regard to jurisdictional claims in published maps and institutional affiliations. 